УДК 577.2

DOI: $10.33184 /$ spbgb-2021-09-21.2

\title{
Роль полиморфного варианта rs4430796 гена HNF1B В формировании предрасположенности к сахарному диабету второго типа и его осложнениям
}

\author{
() Ю.Э. Азарова*, Е.Ю. Клёсова, А.В. Полоников \\ Курский государственный медицинский университет \\ Россия, 305041 г. Курск, улица Карла Маркса, 3. \\ *Email: azzzzar@yandex.ru
}

Установлена ассоциация локуса rs4430796 с риском развития сахарного диабета 2 типа и диабетической нефропатии в русской популяции.

Ключевые слова: HNF1B, однонуклеотидный полиморфизм, индекс массы тела, глутатион, перекись водорода, С-пептид, сахарный диабет 2 типа

Всемирная организация здравоохранения в своем Первом глобальном докладе о ситуации в области неинфекционных заболеваний от 2014 г. определила сахарный диабет (СД) как одну из наиболее опасных неинфекционных эпидемий XXI века наряду с сердечно-сосудистыми и онкологическими заболеваниями, а также хроническими обструктивными болезнями легких (World Health Organization, 2010). Это связано с тем, что заболеваемость диабетом неуклонно растет во всем мире, охватив к 2020 г уже каждого 11-го жителя планеты, что составляет почти 9\% населения Земного Шара. Хорошо известно, что хроническая гипергликемия при СД2 сопровождается развитием окислительного стресса и является одним из ведущих фракторов риска развития мозгового инсульта, инфраркта миокарда, а также является основной причиной потери зрения, нетравматических ампутаций и развития терминальных стадий почечной недостаточности. Факт наличия генетической составляющей в развитии диабета и его осложнений не вызывает сомнений. Одним из полиморфных вариантов, обнаруженных в полногеномном исследовании СД2 в Европейской популяции, является SNP rs4430796 (A>G) в интроне гена HNF1B [2]. HNF1B, или транскрипционный фактор 2 (TCF2), принадлежит к семейству гомеодоменсодержащих транскрипционных фракторов, непосредственно контролирующих развитие поджелудочной железы, печени и почек [3-4]. Функциональные партнеры HNF1B показаны на рисунке 1.

В целом, литературные данные о связи HNF1B с показателями углеводного обмена и редокс-гомеостаза противоречивы. Целью настоящей работы стало изучение ассоциации однонуклеотидного варианта rs4430796 гена HNF1B с биохимическими показателями плазмы крови, а также с риском СД2 и его осложнений у больных и здоровых лиц.

В исследование вошли 1579 больных СД2, получавших стационарное лечение на базе эндокринологического отделения Курской городской клинической больницы скорой медицинской помощи с декабря 2016 по октябрь 2019 гг. Группу контроля составили 1627 здоровых индивидов, - доноров областной станции переливания крови. У всех участников исследования проводили однократный забор 10 мл крови натощак в вакуумные пробирки с ЭДТА (для генетического тестирования) и гепарином лития (для биохимического анализа). Геномную ДНК выделяли колоночным методом с помощью набора QIAamp DNA blood kit (QIAGEN) на автоматической станции QiaCube (QIAGEN, 
Германия). Генотипирование полиморфизма гена $H N F 1 B$ проводили с использованием технологии iPLEX на геномном времяпролетном масс-спектрометре MassArray Analyzer 4 (Agena Bioscience, США). Концентрации перекиси водорода и глутатиона в плазме крови определяли с помощью наборов OxiSelect ROS/RNS Assay kit (Cell Biolabs), GSH/GSSG Assay kit (Abcam) фрлуориметрическим методом на микропланшетном ридере Varioscan Flash (Thermo Fisher Scientific, США). Концентрации глюкозы, гликированного гемоглобина, С-пептида, общего холестерина, липопротеинов высокой и низкой плотности (ЛВП, ЛНП) и триацилглицеролов (ТАГ) определяли на полуавтоматическом биохимическом анализаторе Clima MC-15 (RAL, Испания) стандартными наборами реагентов фрирмы «Диакон-ДС» (Россия). Ассоциации генотипов с риском СД2 изучали методом логистической регрессии с поправкой на пол, возраст и ИМТ с помощью программы SNPStats [5].

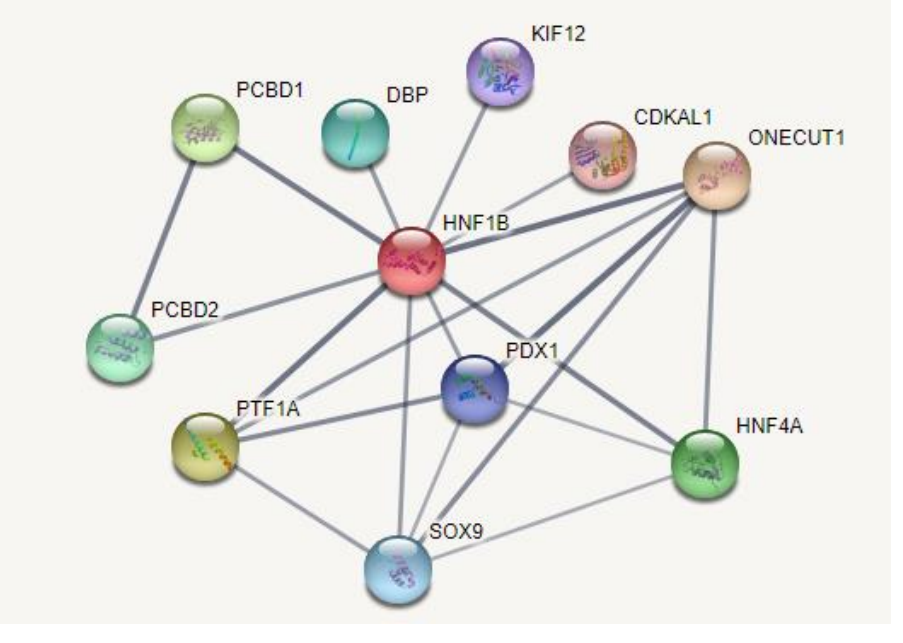

Рис. 1. Сеть белков, образуемая HNF1B: PTF1A - панкреатический транскрипционный фактор, альфа-субъединица; ONECUT1 - гепатоцитарный ядерный фрактор 6; PCBD1 - птерин-4-альфа-карбиноламиндегидратаза 1; PCBD2 - птерин-4-альфракарбиноламиндегидратаза 2; HNF4A - гепатоцитарный ядерный фрактор 4-альфа; DBP - D-сайт связывающий белок; SOX9 - SRY-бокс транскрипционный фрактор 9; PDX1 белок 1 гомеобокса поджелудочной железы/двенадцатиперстной кишки; KIF12 кинезин-подобный белок 12; CDKAL1 - треонилкарбамоиладенозин-TPHKметилтиотрансфераза.

Исследованный SNP находился в соответствии с равновесием Харди-Вайнберга $(P>0,05)$. Линейный регрессионный анализ выявил ассоциацию генотипов $A / G-G / G$ rs4430796 с повышенным риском развития CД2 (OR 1,21, 95Cl 1,04-1,40, P=0,014). Ассоциация осталась значимой и после введения поправок на пол, возраст и ИМТ (OR 1,24, $95 \mathrm{Cl} 1,05-1,47, P=0,011)$. Носители генотипа $\mathrm{G} / \mathrm{G}$ имеют повышенный риск развития диабетической нефропатии (OR 1,53, 95Cl 1,04-2,24, $\mathrm{P}=0,024$ ), тогда как ассоциации полиморфного локуса rs4430796 с другими микро- и макрососудистыми осложнениями СД2 выявлено не было (P>0,05).

При анализе взаимосвязей между генотипами $H N F 1 B$ и биохимическими показателями больных СД2 было обнаружено, что изучаемый SNP ассоциирован с повышенным содержанием перекиси водорода $(P=0,012)$ и более низким уровнем общего глутатиона плазмы $(P=0,041)$ у женщин, тогда как у мужчин с СД2 генотип $G / G$ связан со снижением концентрации $\mathrm{C}$-пептида $(P=0,004)$ и повышением концентрации глюкозы крови $(P=0,015)$. Кроме того, у носителей минорного аллеля $\mathrm{G}$ концентрация мочевой 
кислоты в плазме крови была на 21,1 мкмоль/л выше, чем у носителей генотипа A/A $(\mathrm{P}=0,034)$. Согласно данным ресурса BioGPS, HNF1B экспрессируется в широком спектре тканей и обладает наибольшей экспрессией в поджелудочной железе. Анализ эфрфектов rs 4430796 на уровень метилирования гена $H N F 1 B$, выполненный с помощью инструмента mQTLdb, показал, что альтернативный аллель $G$ связан с гиперметилированием гена при рождении (P=2,08*10-35), в детском ( $P=1,42 * 10-48)$ и взрослом возрасте $\left(P=1,07^{*} 10-45\right)$, а значит, ассоциирован с меньшей транскрипционной активностью HNF1B в эти периоды жизни. С помощью онлайнпрограммы GTEx Portal, мы провели анализ тканеспецифичных эфрфектов минорного аллеля G изучаемого SNP и обнаружили, что носители генотипа G/G имеют более низкую экспрессию HNF1B в поджелудочной железе (Рисунок 2).

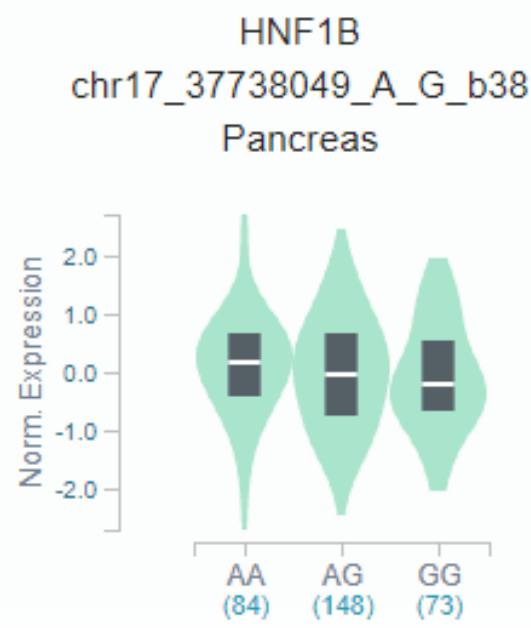

Рис. 2. Экспрессия HNF1B у носителей различных генотипов rs4430796 (GTEx Portal)

Таким образом, в проведенном исследовании впервые в русской популяции установлена ассоциация rs4430796 гена HNF1B с повышенным риском развития СД2 и диабетической нефропатии. Механизм взаимосвязи данных вариантов с заболеванием объясняется менее выраженным синтезом этого транскрипционного фактора у носителей минорного аллеля G, что проявляется снижением концентрации С-пептида, повышением концентрации глюкозы и перекиси водорода в плазме крови. Полученные данные открывают перспективы для дальнейшего изучения генетико-биохимических особенностей метаболизма при СД2 и поиска новых молекулярных мишеней для антиоксидантной и сахароснижающей терапии и профилактики болезни.

Работа выполнена при финансовой поддержке Российского научного фонда (проект № 20-15-00227).

\section{Литература}

1. World Health Organization et al. Global status report on noncommunicable diseases 2014. - World Health Organization, 2014. - №. WHO/NMH/NVI/15.1.

2. Gudmundsson J., Sulem P., Steinthorsdottir V., Bergthorsson J.T., Thorleifsson G., Manolescu A. et al. Two variants on chromosome 17 confer prostate cancer risk, and the one in TCF2 protects against type 2 diabetes. Nat Genet 2007; 39: 977-983. 
3. Edghill E.L., Bingham C., Ellard S., Hattersley A.T. Mutations in hepatocyte nuclear factor-1beta and their related phenotypes. J Med Genet 2006; 43: 84-90. doi.org/10.1136/jmg.2005.032854.

4. Wu G., Bohn S., Ryffel G.U. The HNF1Beta transcription factor has several domains involved in nephrogenesis and partially rescues Pax8/lim1-induced kidney malformations. Eur J Biochem 2004; 271: 3715-3728. doi.org/10.1111/j.1432-1033.2004.04312.x.

5. Solé X., Guinó E., Valls J., Iniesta R., Moreno V. SNPStats: a web tool for the analysis of association studies. Bioinformatics 2006; 22(15): 1928-1929. doi.org/10.1093/bioinformatics/btl268.

The role of the polymorphic variant rs4430796 at HNF1B gene in the formation of predisposition to type 2 diabetes and its complications

\author{
I. Azarova*, E. Klyosova, A. Polonikov \\ Kursk State Medical University \\ 3 Karl Marx Street, 305041 Kursk, Russia.
}

*Email:azzzzar@yandex.ru

An association of the rs4430796 locus with the risk of developing type 2 diabetes and diabetic nephropathy in the Russian population has been established.

Keywords: HNF1B, single nucleotide polymorphism, body mass index, glutathione, hydrogen peroxide, C-peptide, type 2 diabetes mellitus. 